\title{
Geri Dönüştürülmüş Farklı Tip İnşaat ve Yıkıntı Atıklarının Kompaksiyon Özelliklerinin İncelenmesi
}

\author{
${ }^{* 1}$ Hüseyin Çolakoğlu, ${ }^{1}$ Bahadır Ok ve ${ }^{2}$ Talha Sarıcı \\ ${ }^{1}$ Adana Alparslan Türkeş Bilim ve Teknoloji Üniversitesi, Mühendislik Fakültesi, İnşaat Mühendisliği Bölümü, \\ Adana, Türkiye. \\ ${ }^{2}$ İnönü Üniversitesi, Mühendislik Fakültesi, İnşaat Mühendisliği Bölümü, Malatya, Türkiye.
}

\begin{abstract}
Özet
Agregalar dünyada inşaat sektöründe en fazla tüketilen malzemedir. Günümüzde hızla büyüyen inşaat endüstrisiyle paralel olarak agregaya olan ihtiyaçta sürekli artmaktadır. Tüketim potansiyeli oldukça yüksek olmasına rağmen agregalar diğer doğal kaynaklar gibi sınırlı kaynaklara sahiptir. Doğal agregaların üretim maliyeti, çıkarıldığı alanda ekolojik tahribatı gibi ekonomik ve çevresel etkiler göz önüne alındığında doğal agregalara alternatif malzeme arayışları başlamıştır. Doğal agregaya alternatif olarak görülen inşaat ve yıkıntı atıklarının geri dönüştürülerek kullanılması sürdürülebilir bir çevre için oldukça önemlidir. $\mathrm{Bu}$ çalş̧mada, çeşitli dolgularda doğal agrega yerine geri dönüştürülmüş malzemelerin kullanılabilirliğinin araştırılması için geri dönüştürülmüş üç farklı tipte dört inşaat ve yıkıntı atı̆̆ının kompaksiyon özellikleri araştırılmıştır. Elde edilen sonuçlar dolgularda kullanılan bir çeşit doğal agrega malzemesi ile karşılaştırılmıştır. Çalışma sonucunda beton bazlı ve nispeten yüksek dayanıma sahip bileşenlerden oluşan inşaat ve yıkıntı atıklarının kil bazlı veya düşük dayanıma sahip bileşenlerden oluşan atıklara göre doğal agregalara daha yakın davranış gösterdiği görülmüştür.
\end{abstract}

Anahtar kelimeler: İnşaat ve yıkıntı atığı, geri dönüştürülmüş beton agrega, geri dönüştürülmüş tuğla, kompaksiyon.

\section{Giriş}

Dünyada üretilen atıkların ve kullanılan doğal kaynakların yaklaşık olarak yarısından inşaat endüstrisi sorumludur [1]. Son yıllarda inşaat sektörü hızla büyümekte ve buna paralel olarak doğal kaynakların tüketimi artmaktadır. Örneğin 2006 yılında dünya genelinde 31 milyar ton beton tüketilmiştir ki bu miktar suyun ardından en fazla tüketilen materyalin beton olduğunu ifade etmektedir [2]. İnşaat mühendisliği uygulamalarında en çok sarf edilen doğal kaynaklardan biri agregalardır [1]. Sektördeki büyüme ile doğru orantılı olarak da doğal agregalara olan ihtiyaçta artmıştır [3]. Günümüzde taş ocaklarının agrega talebini karşılamakta yetersiz kaldığı durumlarda ve sınırlı rezervleri azaldığında yeni taş ocakları açılarak agrega ihtiyacı karşılanmaya çalışılmaktadır. Bazen ulaşım maliyetlerinden dolayı da yeni taş ocakları açılmaktadır. Ancak taş ocakları geri dönüşü olmayan doğal tahribatlara neden olmaktadır. Ayrıca rezervleri de sınırsız değildir. $\mathrm{Bu}$ sebeple agrega ihtiyacını karşılamak için sürdürülebilir çözümler önem kazanmaktadır. Bu bağlamda araştırmacılar doğal agregalara alternatif üretmek için çözüm

\footnotetext{
* Corresponding author: Address: Adana Alparslan Türkeş Bilim ve Teknoloji Üniversitesi, Mühendislik Fakültesi, İnşaat Mühendisliği Bölümü, 01250, Adana TURKEY. E-mail address: huseyincolakoglu.hc@gmail.com, Phone: $+905443052580$
} 
arayışına girmişlerdir [1-25].

İnşaat endüstrisinde ortaya çıkan atıkların tamamına yakını, inşaat ve yıkıntı atıkları (IYA) olarak adlandırılmaktadır. IYYA; beton, tuğla, ahşap, alçı, cam ve bitüm gibi atık malzemeleri heterojen veya homojen olarak içeren karışımlar olarak tanımlanabilir. İYA'lar dünya genelinde devasa miktarda bulunmakta ve her geçen gün bu miktar sürekli olarak artmaktadır örneğin bu kapsamdaki atık miktarı Avrupa'da $310 \sim 720$ milyon ton/yıl, ülkemizde $4 \sim 5$ milyon ton/yıl ortaya çıkmaktadır. Ortaya çıkan IYYA'ların depolanma ve bertaraf edilmesi hem çevresel hem de ekonomik olarak büyük olumsuz sonuçlar doğurmaktadır bu sebeple IYYA'ların geri dönüştürülerek tekrar kullanıması sürdürülebilir çevre ve ekonomi için faydalı olacağı düşünülmektedir. IYYA'larının önemli bir bölümünün geri dönüştürülebilir özelliğe sahip olduğu birçok araştırmacı tarafından ifade edilmiştir [1, 22]. Ayrıca Avrupa Komisyonu'da geri dönüştürülen İYA'ların tekrar kullanılma potansiyelinin yüksek olduğu belirtmişlerdir [26]. Ülkeler ve bölgesel seviyelerde hükümetler tarafından IY'A'ların geri kazanılmasının arttırılması için bazı çalışmalar yürütülmektedir [3].

Ülkemizde 2012 yılında çıkan 6306 sayılı “Afet Riski Altındaki Alanların Dönüştürülmesi Hakkında Kanun’ ile riskli olduğu düşünülen yapıların yıkılarak yerine yeni yapıların yapılması teşvik edilmektedir. Bunun yanında 2004 yılında çıkan 25406 sayılı "Hafriyat Toprağı, İnşaat ve Yıkıntı Atıklarının Kontrolü Yönetmeliği', ile ortaya çıkan atıkların geri dönüştürülerek geri kazanılması önerilmektedir. Ek olarak 2019 yılında çıkan 30829 sayılı "Sıfır atık yönetmeliği', ile atıkların geri kazanılmasının yaygınlaştırılması konusunda önemli bir adım atılmıştır [1]. Bu bağlamda kentsel dönüşüm sonrasında çıkacak atıkların geri dönüştürülerek tekrar kullanılması için yollar araştırmak önemli hale gelmiştir.

Araştırmacılar IYYA'ların bulunduğu bölgeye ve içerdiği malzemeye göre farklılık göstermesinden dolayı geri kazanılmış IYYA'ların mühendislik özelliklerinin değişken olacağını düşünerek IYYA'larının doğal agregalar yerine kullanımı açısından güvenirliğini sorgulamışlardır. Bu sebeple araştırmacılar IYYA'larının geoteknik mühendisliği uygulamalarında doğal malzemeler yerine kullanılabilmesi durumunun titizlikle değerlendirilmesinin önemli olduğunu ifade etmişlerdir $[6,7,8,10,13,15]$. Araştırmacılar IYYA'ların geoteknik mühendisliği uygulamalarında tekrar kullanılmasının arttırılması için daha fazla çalışmaya ihtiyaç duyulduğunu belirtmişlerdir. Ayrıca araştırmacılar İYA'ların yol veya çeşitli dolgularda doğal agregaya alternatif olma açısından büyük bir potansiyeli olduğunun öngörerek bu konu üzerine bir çok çalışma yürütmüşlerdir [5-25]. Bu çalışmaların sonucunda genel olarak IYYA'ların doğal agregalara göre daha düşük bir performans gösterdiği buna rağmen çeşitli tasarım limitlerinin altında kalmadığg için doğal agregalara alternatif olarak kullanılabileceği belirtilmiştir. Ayrıca bu çalışmalarda atık agregaların içeriğinin performansını önemli ölçüde etkilediği ifade edilmiştir. Bu nedenle IYYA'ların içerdiği atık malzemelerin ayrı ayrı mühendislik özellikleri belirlenmesi IYYA'larının genel davranışının belirlenmesi adına önem arz ettiği sonucuna varılmıştır. Bu çalışmada IYYA'larının içerebileceği farklı dayanımdaki beton ve tuğla atıkları üzerinde çalışma yapılması planlanmıştır.

Ülkemizde yapı inşa edilirken beton dökümü sırasında yapı denetim kontrolünde TS EN 12350-1 "Taze Betondan Numune Alma' [27] standardına göre dökülen beton miktarına göre farklı sayılarda beton küp numuneler alınmaktadır. Alınan beton küp numuneler 7 ve 28 günlük kürleme 
sonunda beton basınç deneyine tabi tutulmaktadır. Laboratuvarda test edilen beton küp numuneler test sonrasında atık duruma gelmektedir. Ayrıca kullanım amacına göre özel kesitlere sahip, genellikle düşük dayanımlı betondan üretilen ve genellikle kaldırım ve yollarda kullanılan kilit parkeler, üretim hatası ile standardına uygun üretilmediklerinde, servis ömrünü tamamladıklarında veya restorasyon sırasında deforme olduklarında atık hale gelmektedirler. Dayanımları laboratuvar deneyleri ile belirlenen beton numunelerden ve atık parkelerden elde edilecek atık agrega numuneleri üzerinde araştırma yapmanın benzer atıkları dayanımlarına göre karşılaştırma açısından faydalı olacağı ön görülmüştür. Bunların dışında kentsel dönüşüm projeleri sebebi ile yapılaşmanın her geçen gün ivme kazanacağı ülkemizde büyük miktarda küp beton numune atığ oluşacağı düşünülmektedir.

Tuğla antik zamanlardan beri çok kullanılan kil yapı taşlı bir yapı malzemesidir. Tuğlanın tek başına çok büyük miktarda atık durumda bulunması pek rastlanılan bir durum olmamakla birlikte heterojen yapıdaki IYYA'ların neredeyse hepsinde bulunmaktadır [10,14,26,28,29,30,31]. Yaygın olarak kullanılan inşaat malzemelerine göre içeriğindeki kilden dolayı su emme oranları yüksek çıkmaktadır [19]. Bu nedenle tuğla içeren heterojen yapıdaki atık malzemenin özelliklerinin daha iyi anlaşılması için tuğlanın mühendislik özelliklerinin daha iyi araştırılması gerekmektedir.

$\mathrm{Bu}$ çalışmada genellikle IYYA'larının içeriğinde bulunan atık beton ve atık tuğlanın dolgularda doğal agregalar yerine kullanılabildiğini özellikle kompaksiyon özellikleri açısından araştırılmıştır. Bu sebeple atık beton, atık tuğla ve atık kilit parkeden elde edilen 4 ayrı geri dönüştürülmüş IYA malzemesi üzerinde laboratuvar deneyleri (su emme, birim hacim ağırlık, modifiye kompaksiyon, sıkılık) yapılmıştır. Ayrıca elde edilen sonuçlar doğal agrega karşılaştırılarak değerlendirmelerde bulunulmuştur.

\section{Malzeme ve Yöntem}

\subsection{Inşaat ve Yıkıntı Atıkları Tipleri ve Temini}

Bu çalışmada, iki farklı dayanıma sahip geri dönüştürülmüş beton agrega (RCA), bir çeşit geri dönüştürülmüş tuğla $(\mathrm{CB})$ ve bir çeşit atık kilit parke taşı $(\mathrm{KP})$ olmak üzere dört farklı geri dönüştürülmüş inşaat ve yıkıntı atığı malzemeden numuneler elde edilmiştir. Geri dönüştürülmüş beton agregalar, yapıların beton basınç dayanımlarının projeye uygunluğunun kontrol edilmesi için inşa aşamasında alınan atık küp numunelerden elde edilmiştir. $\mathrm{Bu}$ yöntemle alınan atık beton numunesini basınç dayanımına göre değerlendirme imkânı kazanılmıştır. Bu amaçla Osmaniye'deki laboratuvarlardan 28 günlük kürleme sonunda beton basınç dayanımı testine tabi tutulmuş ve beton sınıfı C30 ve C40 olarak belirlenmiş atık küp numuneler elde edilmiştir. Beton sinifi C30 ve C40 olan numunelerden RCA30 ve RCA40 adı verilen agrega numuneleri elde edilmiştir. Geri dönüştürülmüş tuğlalar yapıda kullanmak için imal edilip depolanan ve 35 yıl boyunca kullanılmamasından dolayı atık hale gelen tuğlalardan elde edilmiştir. Atık kilit parke taşları Osmaniye'deki bir konutun peyzaj düzenlenmesi için kullanılan 15 yıllık bir süreç sonrasında deforme olması sebebi ile kullanım yerinden çıkartılması sonucunda atık haline gelen parke taşlarından elde edilmiştir. Çalışmada için elde edilen ve yukarında bahsi geçen atık beton küp numuneleri, atık tuğlalar ve atık parke taşları Şekil 1'de gösterilmiştir. 


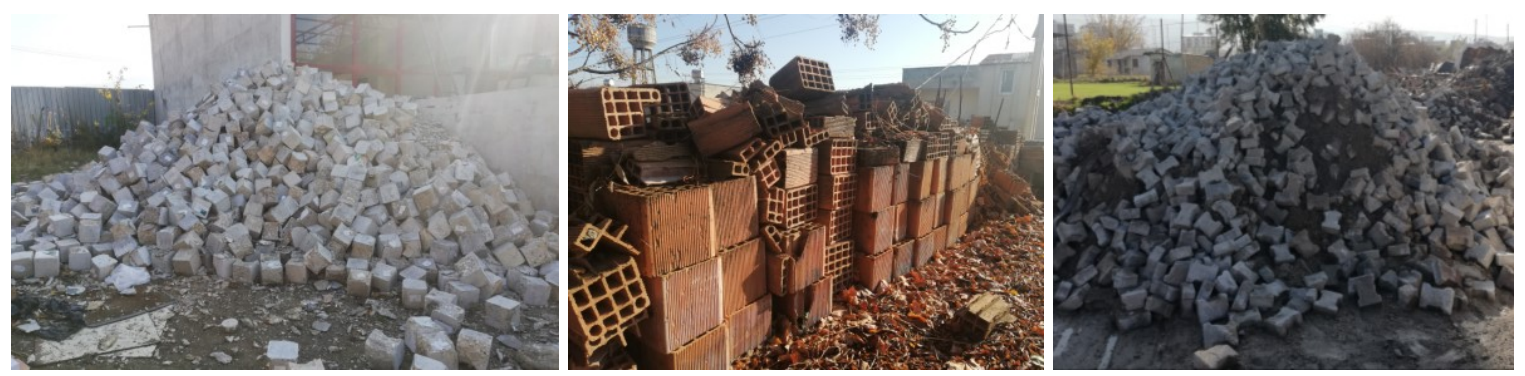

Şekil 1. Atık beton küp numuneleri, atık tuğlalar ve atık parke taşları

RCA30 ve RCA40 beton basınç dayanımı testi sonrasında beton sınıfı C30 ve C40 olarak belirlenen numunelerden elde edildiği için basınç dayanımları bilinmektedir. Çalışmada kullanılan bir diğer beton yapı taşlı atık malzemesi parke taşlarının dayanımlarının belirlenmesi için ise parke yarma deneyi (TS 2824 EN 1338) [32] yapılmıştır (Şekil 2). Bir gurup atık kilit parke taşı numunesi üzerinde yapılan parke yarma deneyleri sonucunda parkelerin ortalama yarmada çekme dayanımı 3.85 MPa olarak belirlenmiştir.

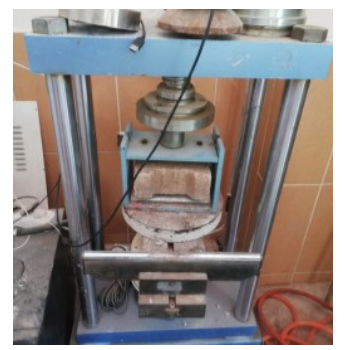

Şekil 2. Atık kilit parke taşlarının yarmada çekme dayanımlarının belirlenmesi

\subsection{Doğal Agrega Temini}

Çalışma kapsamında temin edilen atık agregaların dolgularda kullanılabilmesi durumunun araştırılabilmesi adına kıyas yapabilmek için atık agregalar üzerinde yapılan deneyler dolgularda sıkça kullanılan bir çeşit doğal agrega numunesi üzerinde de gerçekleştirilmiştir. Bu sebeple Adana ilindeki bir taş ocağından doğal agrega numunesi (NA) temin edilmiştir (Şekil 3).

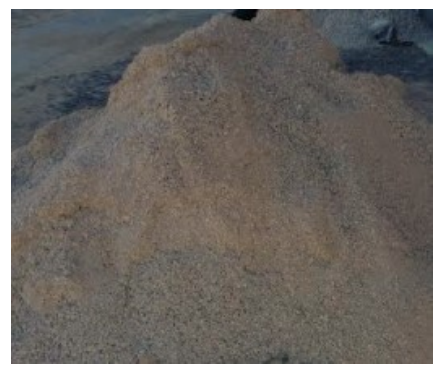

Şekil 3. Doğal agrega numunesi

\subsection{Inşaat ve Yıkıntı Atıklarının ve Doğal Agregaların Uygun Gradasyona Getirilmesi}

Temin edilen atık malzemeler Adana Alparslan Türkeş Bilim ve Teknoloji Üniversitesi laboratuvarlarında mevcut iki farklı çeneli kırıcı ile kırılarak 9-16 mm, 5-9mm ve 0-5mm olmak 
üzere üç farklı çap aralığında numuneler elde edilmiştir (Şekil 4). Ayrıca doğal agregalarda kaynağından benzer şekilde üç farklı çap aralığında temin edilmiştir. Üç farklı çapta bulunan dört çeşit atık agrega ile bir çeşit doğal agrega için elek analizleri (ASTM D 422-63) [33] yapılarak ASTM D 1241-00 [34] standardına göre C gradasyona uygun olacak şekilde karışım oranları belirlenmiştir. Numuneler belirlenen karışım oranlarına göre karıştırılmış ve sonra tekrar elek analizine tabi tutulmuştur. Elde edilen dört çeşit atık agrega numunesi (RCA40, RCA30, CB ve KP) ile bir çeşit doğal agrega numunesi (NA) birleşmiş zemin sınıflandırma sistemine (ASTM D 2487-11) [35] göre GW olarak sınıflandırılmıştır. Ayrıca elek analizleri sonucu elde edilen nihai gradasyonlar Şekil 5'te sunulmuştur. Karışım sonrasında elde edilen atık RCA30, RCA40, CB ve KP ile doğal (NA) malzemelerin görüntüsü Şekil 6’da gösterilmiştir.

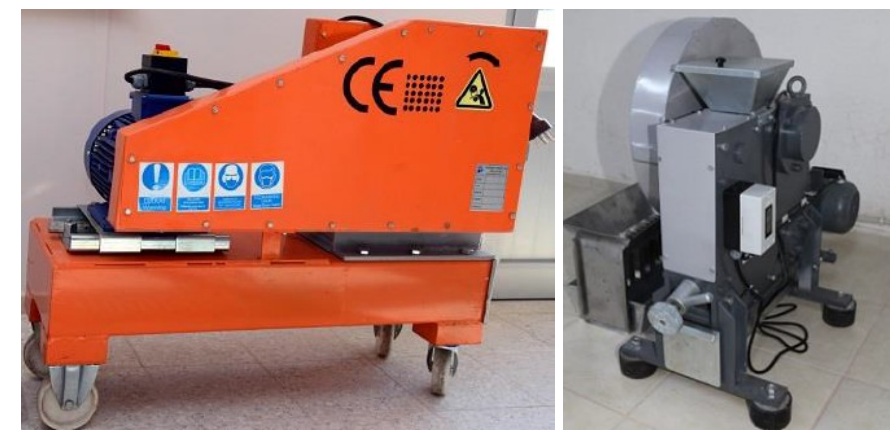

Şekil 4. Büyük (soldaki) ve küçük (sağdaki) ağız açıklıklı çeneli kırıcı
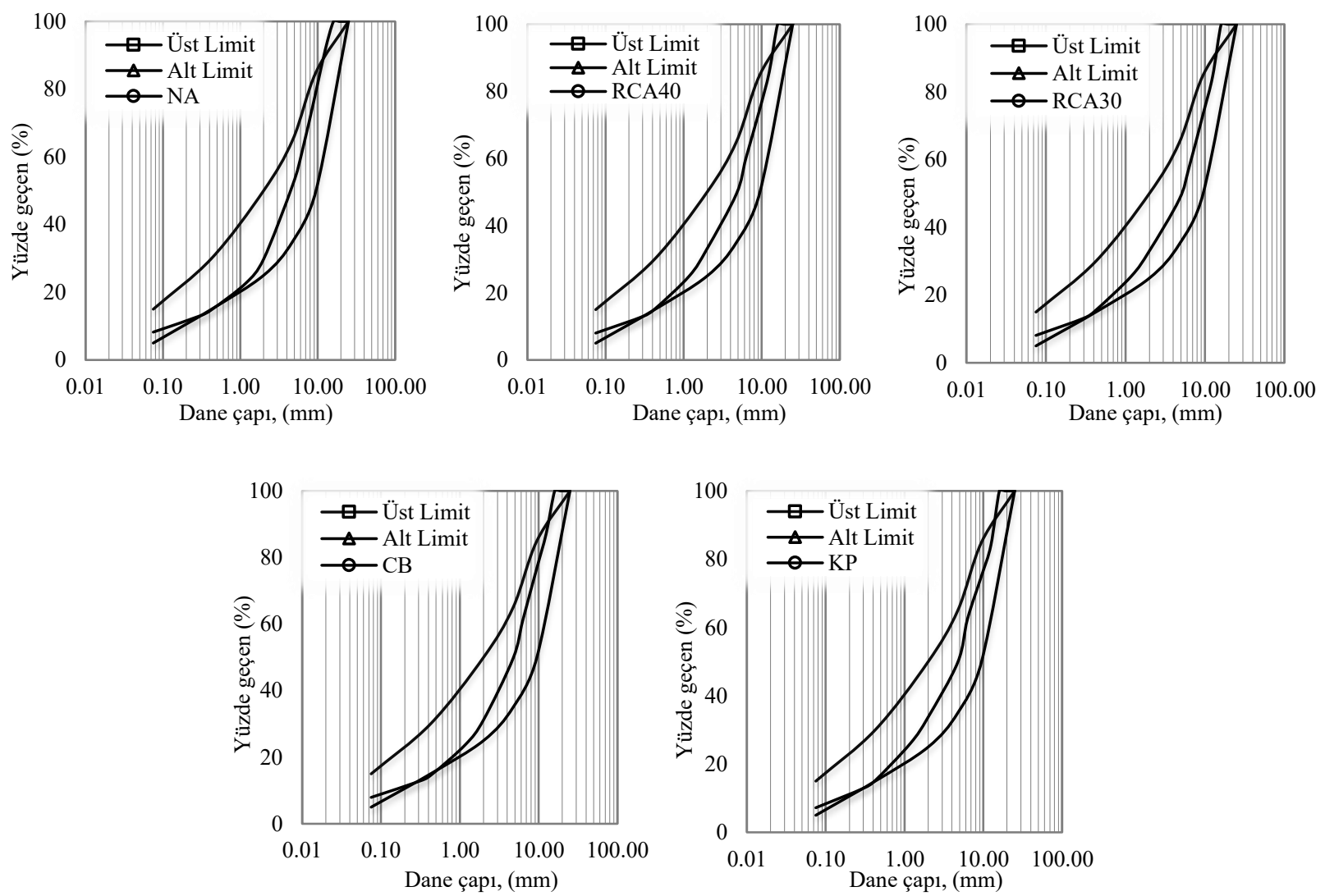

Şekil 5. Karışım sonrası elde edilen gradasyon eğrileri 

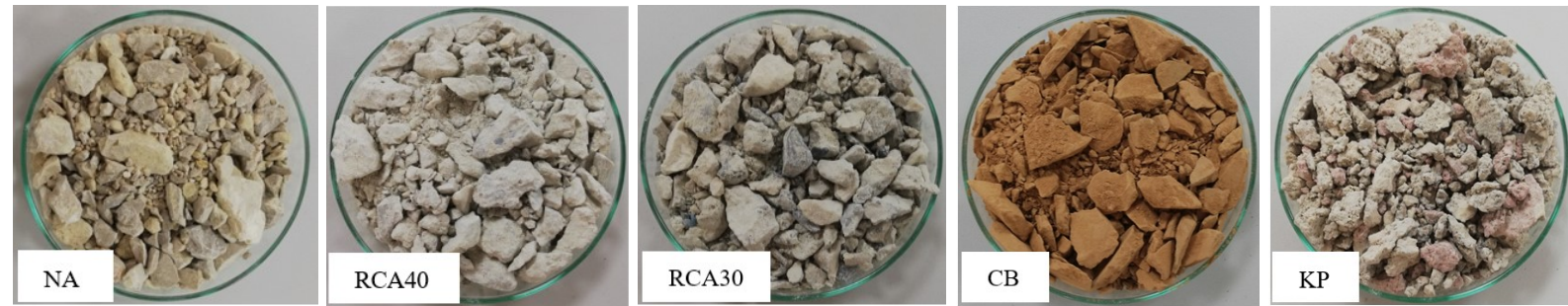

Şekil 6. Doğal agrega ve geri dönüştürülmüş atık malzemeler

\section{Sonuçlar}

\subsection{Attk ve doğal malzemelerin fiziksel özellikleri}

Belirlenen gradasyona getirilen atık (RCA40, RCA30, CB ve KP) ve doğal (NA) agrega malzemelerin fiziksel özelliklerinin karşılaştırmak için laboratuvarda dane birim hacim ağırlığ 1 ve su emme deneyleri yapılmıştır [36-38]. Elde edilen sonuçlar Tablo 1'de özetlenmiştir.

Tablo 1. Atık ve doğal agrega malzemelerin fiziksel özellikleri

Dane birim hacim ağırlık $\quad$ Su emme (\%) $\left(\mathrm{kN} / \mathrm{m}^{3}\right)$

\begin{tabular}{ccccc} 
& Kaba tane & İnce tane & Kaba tane & İnce tane \\
\hline NA & 26.59 & 26.59 & 0.83 & 3.31 \\
\hline RCA40 & 26.11 & 25.98 & 5.47 & 10.52 \\
\hline RCA30 & 26.09 & 26.13 & 5.38 & 9.10 \\
\hline CB & 26.49 & 27.27 & 16.71 & 20.24 \\
\hline KP & 25.89 & 26.60 & 5.12 & 5.65 \\
\hline
\end{tabular}

\subsection{Attk ve doğal malzemelerin kompaksiyon özellikleri}

Belirlenen gradasyona getirilen atık (RCA40, RCA30, CB ve KP) ve doğal (NA) agrega malzemelerin kompaksiyon özelliklerinin kıyaslanabilmesi için modifiye proktor deneyleri (ASTM D 1557) [39] yapılarak numunelerin maksimum kuru birim hacim ağıllıkları $\left(\gamma_{\mathrm{kmaks}}\right)$ ve optimum su içerikleri $\left(\omega_{\mathrm{opt}}\right)$ belirlenmiştir. Numunelerin kompaksiyon parametreleri $\left(\gamma_{\mathrm{kmaks}}\right.$ ve $\left.\omega_{\mathrm{opt}}\right)$ Tablo 2'de özetlenmiştir. Ayrıca numunelerin kompaksiyon eğrileri Şekil 7'de verilmiştir.

Tablo 2. Atık ve doğal agrega malzemelerin kompaksiyon parametreleri

\begin{tabular}{ccc} 
& $\gamma_{\text {kmaks }}\left(\mathrm{kN} / \mathrm{m}^{3}\right)$ & $\omega_{\text {opt }}(\%)$ \\
\hline NA & 22.37 & 6.00 \\
\hline RCA40 & 18.97 & 11.61 \\
\hline RCA30 & 19.13 & 10.16 \\
\hline CB & 15.55 & 20.13 \\
\hline KP & 18.55 & 13.00 \\
\hline
\end{tabular}




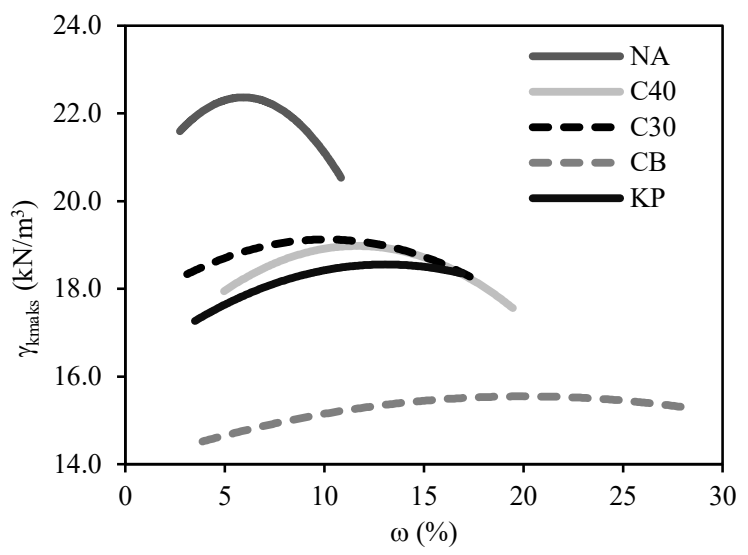

Şekil 7. Atık ve doğal agrega malzemelerin kompaksiyon eğrileri

\subsection{Attk ve doğal malzemelerin farklı rölatif sıkılıklara göre birim hacim ăğtlıkları}

Belirlenen gradasyona getirilen atık (RCA40, RCA30, CB ve KP) ve doğal (NA) agrega malzemelerinin sıkışmanın bir ölçütü olarak sıkı ve gevşek durumdaki birim hacim ağırlıklarının karşılaştırılması için maksimum ve minimum boşluk oranları ( $e_{\max }$ ve $e_{\min }$ ) belirlenerek sıkılık deneyleri (ASTM D 4254-00) [40] yapılmıştır. Buna göre numunelerin \%35 rölatif sıkılıktaki (gevşek durum $\gamma_{\text {ngevşek }}$ ) ve $\% 95$ rölatif sıkılıktaki (sıkı durum $\gamma_{\text {nskkı) }}$ birim hacim ağırlıkları elde edilmiştir. Elde edilen sıkı ve gevşek durumdaki birim hacim ağırlı̆̆ değerleri Tablo 3 'te özetlenmiştir.

Tablo 3. Atık ve doğal agrega malzemelerin sıkı ve gevşek durumdaki birim hacim ağırlıkları

\begin{tabular}{lcc} 
& $\gamma_{\text {ngevșek }}(\mathrm{Dr}=\% 35)\left(\mathrm{kN} / \mathrm{m}^{3}\right)$ & $\gamma_{\text {nskk1 }}\left(\mathrm{Dr}=\%\right.$ 95) $\left(\mathrm{kN} / \mathrm{m}^{3}\right)$ \\
\hline NA & 19.78 & 21.48 \\
\hline RCA40 & 17.47 & 19.36 \\
\hline RCA30 & 16.79 & 19.05 \\
\hline CB & 12.92 & 14.51 \\
\hline KP & 15.69 & 17.66 \\
\hline
\end{tabular}

\section{Tartışma}

Atık (RCA40, RCA30, CB ve KP) ve doğal (NA) agrega malzemelerin dane birim hacim ağırlıkları incelendiğinde malzemelerin dane birim hacim ağırlkklarının birbirine oldukça yakın olması ile birlikte NA'nın dane birim hacim ağıllığının diğer atık agregalara göre daha yüksek olduğu görülmüştür. Bu bakıma en düşük dane birim hacim ağırlığı nispeten düşük dayanımlı olan KP'de elde edilmiştir. Ancak numunelerin su emme değerlerinde keskin bir ayrım görülmüştür. Beton bazlı RCA30, RCA40 ve KP'nin su emme değerleri birbirine oldukça yakın iken kil bazlı CB'nin su emme değeri hem kaba hem de ince tanelerde oldukça yüksek değerlere ulaşmıştır. Kaba daneler için CB'nin su emme değeri doğal agregalardan yaklaşık 20 katı diğer atık agregaların yaklaşık 6 katı kadardır. Bunun sebebinin özellikle tuğlanın parçalanması ile açığa çıkan CB'nin içerdiği kil malzemelerden olduğu düşünülmektedir. Kil bazlı atıkların su emmesinin fazla olduğu diğer bazı araştırmacılar tarafından da raporlanmıştır [3, 31]. Karayolları Teknik Şartnamesine göre temel ve alt temel malzemesinin su emmesi $\% 3$ ve \%3.5'tan fazla olamamasi gerekmektedir [41]. Bu 
durumda RCA30, RCA40 ve KP karayolu teknik şartnamesi sınırına nispeten yakın su emme değerlerine sahipken CB bu sınırdan oldukça uzak bir su emme değerine sahip olmuştur.

Modifiye kompaksiyon deneyleri analiz edildiğinde NA'nın yüksek $\gamma_{\mathrm{kmaks}}$ değeri ve düşük $\omega_{\mathrm{opt}}$ değerine sahip olduğu görülmüştür. NA'nın $\gamma_{\text {kmaks }}$ değeri kendine en yakın atık agreganın (RCA30) $\gamma_{\text {kmaks }}$ değerinden yaklaşık \%17 daha fazla iken $\omega_{\text {opt }}$ yaklaşık $\% 70$ az çıkmıştır. RCA30 ve RCA40 numunelerinin kompaksiyon parametreleri birbirine oldukça yakın iken nispeten daha az dayanımlı $\mathrm{KP}$ numunesinin $\gamma_{\mathrm{kmaks}}$ değeri RCA30 ve RCA40'a göre biraz düşük $\omega_{\text {opt }}$ değeri ise biraz yüksek olarak elde edilmiştir. Bu aradaki farkın KP'nin RCA30 ve RCA40'a göre daha fazla boşluk içermesinden ve numunelerin dane birim hacim ağırlıklarının arasındaki küçük farktan kaynaklandığı ön görülmektedir. Bununla birlikte CB'nin $\gamma_{\mathrm{kmaks}}$ değeri diğer numunelere göre oldukça düşük iken $\omega_{\text {opt }}$ değeri de oldukça yüksek olarak elde edilmiştir. Bu durumun CB'nin yüksek su emme kapasitesinden kaynaklandığı düşünülmektedir.

NA'nın sıkı ve gevşek durumdaki birim hacim ağırlıkları atık (RCA40, RCA30, CB ve KP) malzemelerden daha yüksek iken RCA40 ve RCA30 birbirine yakın değerlere sahip olmuştur. Ancak nisbeten düşük dayanıma sahip beton bazlı KP ve kil bazlı CB'nin sıkı ve gevşek durumlardaki birim hacim ağırlıkları diğerlerinden daha düşük olarak elde edilmiştir.

\section{Değerlendirme}

Çalışma sonucunda elde edilen önemli sonuçlar aşağıda özetlenmiştir.

- Hem kompaksiyon hem de fiziksel özellikler açısından NA malzemelerin beton bazlı atık malzemelerden kısıtlı bir miktar, kil bazlı atık malzemelerden ise belirgin bir miktarda daha iyi sonuçlara sahip olduğu görülmüştür.

- IYYA'nın içereceği CB miktarı IYYA'dan üretilecek agregaların su emme oranlarının büyük ölçüde etkileyecektir. Buna karşın beton malzemesinin su emmesi CB'ye göre oldukça düşük olduğundan IYYA'nın içeriğinde beton bazlı atıkların fazla olması kil bazlı tuğla gibi atıkların diğer atıklara nispeten az olması dolgunun aşırı su emmesinin önüne geçilebilmesi açısından önemli olduğu düşünülmektedir.

- Beton bazlı atık malzemelerde dayanımı yüksek olan RCA40 ve RCA30 birbirine yakın fiziksel ve kompaksiyon özelliklerine yakın olduğu beton sınıfı arasındaki farkın fiziksel özellik ve kompaksiyon parametreleri açısından aşırı bir fark yaratmadığı ancak nispeten dayanımı düşük olan KP'nin RCA40 ve RCA30'a göre biraz daha düşük performans gösterdiği görülmüştür. Bu sebeple atık dayanımındaki aşırı değişimin malzemenin fiziksel ve kompaksiyon özellikleri üzerinde etkili olduğu düşünülmektedir.

- Aşırı su emme değeri CB’nin fiziksel ve kompaksiyon parametrelerini olumsuz anlamda etkilediği ve bu malzemelerin bir karışım içinde olmadan yalnız başına dolgu malzemesi olarak kullanılması isteniyorsa bu dezavantajların göz önünde bulundurulması gerektiği açığa çıkmıştır. 
- Hem fiziksel özellik hem de sıkışma özellikleri açısından doğal agregaya en yakın performans yüksek dayanımlı beton bazlı atıklardan (RCA30 ve RCA40) elde edilmiştir. Araştırılan diğer atık malzemelerin (CB ve KP) IYYA'ları içindeki oranını artması IYYA'nın performansını olumsuz etkileyebileceği düşünülmektedir.

\section{Kaynaklar}

[1] Ok B. Geosentetiklerle Güß̧lendirilmiş İnşaat ve Yıkıntı Atığı Dolguların Statik ve Tekrarlı Yükler Altındaki Davranışının İncelenmesi. Doktora Tezi, Çukurova Üniversitesi, Fen Bilimleri Enstitüsü; 2018.

[2] Maçin KE, Demir İ. Kentsel dönüşüm sürecinde İstanbul'da inşaat ve yıkıntı atıkları yönetimi; 2018.

[3] Arulrajah A, Piratheepan J, Aatheesan T, Bo MW. Geotechnical Properties of Recycled Crushed Brick in Pavement Applications. J. Mater. Civ. Eng 2011; 23(10): 1444-1452.

[4] O'Mahony MM, Milligan GWE. Use of recycled materials in subbase layers. Transportation Research Record 1991; 1310.

[5] Bennert T, Papp W, Maher A, Gucunski N. Utilization of Construction and Demolition Debris under Traffic-Type Loading in Base and Subbase Applications. Transportation Research Record: Journal of the Transportation Research Board 2000; 1714: 33-39.

[6] Nataatmadja A, Tan YL. Resilient response of recycled concrete road aggregates. Journal of Transportation Engineering 2001; 127(5): 450-453.

[7] Molenaar AA, van Niekerk AA. Effects of gradation, composition, and degree of compaction on the mechanical characteristics of recycled unbound materials. Transportation Research Record 2002; 1787: 73-82.

[8] Sivakumar V, McKinley JD, Ferguson D. Reuse of Construction Waste: Performance under Repeated Loading. Proc. Inst. Civ. Eng. Geotech. Eng. 2004; 157:91-96.

[9] Poon CS, Chan D. Feasible Use of Recycled Concrete Aggregates and Crushedclay Brick As Unbound Road Sub-Base. Constr. Build. Mater. 2006; 20:578-585.

[10] Santos ECG, Vilar OM. Use of Recycled Construction and Demolition Wastes (RCDW) As Backfill of Reinforced Soil Structures. In: Proceedings of the Fourth European Geosynthetics Conference, EUROGEO 4, September 7-10, Edinburg, Scotland; 2008.

[11] Leite FC, Motta RS, Vasconcelos KL, Bernucci L. Laboratory Evaluation of Recycled Construction and Demolition Waste for Pavements. Constr. Build.Mater. 2011; 25:2972-2979. [12] Gabr AR, Cameron DA. Properties of Recycled Concrete Aggregate for Unbound Pavement Construction. Journal of Materials in Civil Engineering (ASCE) 2012; 24(6):754-764.

[13] Barbudo A, Agrela F, Ayuso J, Jiménez JR, Poon CS. Statistical Analysis of Recycled Aggregates Derived from Different Sources for Sub-Base Applications. Constr. Build. Mater. 2012; 28:129-138.

[14] Cerni G, Cardone F, Bocci M. Permanent Deformation Behaviour of Unbound Recycled Mixtures. Construction and Building Materials 2012; 37:573-580.

[15] Arulrajah A, Piratheepan J, Disfani MM, Bo MW. Geotechnical and Geoenvironmental Properties of Recycled Construction and Demolition Materials in Pavement Subbase Applications. Journal of Materials in Civil Engineering 2013; 25(8):1077-1088.

[16] Arulrajah A, Rahman MA, Piratheepan J, Bo MW, Imteaz MA. Interface Shear Strength Testing of Geogrid-Reinforced Construction Anddemolition Materials. Adv. Civil Eng. Mater. 
2013; 2(1):189-200.

[17] Arulrajah A, Piratheepan J, Disfani MM. Reclaimed Asphalt Pavement and Recycled Concrete Aggregate Blends in Pavement Subbases: Laboratory and Field Evaluation. Journal of Materials in Civil Engineering 2014; 26(2):349-357.

[18] Rahman MA, Arulrajah A, Piratheepan J, Bo MW, Imteaz MA. Resilient Modulus and Permanent Deformation Responses of Geogrid-Reinforced Construction and Demolition Materials. J Mater Civ Eng. 2014; 26(3):512-519.

[19] Arulrajah A, Rahman MA, Piratheepan J, Bo MW, Imteaz MA. Evaluation of Interface Shear Strength Properties of Geogrid-Reinforced Construction and Demolition Materials Using A Modified Large Scale Direct Sheartesting Apparatus. J. Mater. Civil Eng. 2014; 26:974-982. [20] Disfani MM, Arulrajah A, Haghighi H, Mohammadinia A, Horpibulsuk S. Flexural Beam Fatigue Strength Evaluation Of Crushed Brick As a Supplementary Material in Cement Stabilized Recycled Concrete Aggregates. Constr. Build.Mater. 2014; 68:667-676. [21] Ayan V, Limbachiya MC, Omer JR, Azadani SMN. Compaction Assessment of Recycled Aggregates for Use in Unbound Subbase Application. Journal of Civil Engineering and Management 2014; 20(2):169- 174.

[22] Vieira CS, Pereira PM. Damage Induced by Recycled Construction and Demolition Wastes on the Short-Term Tensile Behaviour of Two Geosynthetics. Transportation Geotechnics 2015; 4:64-75.

[23] Saribas I, Ok B. Seismic performance of recycled aggregate-filled cantilever reinforced concrete retaining walls. Advances in Mechanical Engineering 2019; 11(4), 1687814019838112. [24] Sarıcı T. Puzolan ile güçlendirilmiş inşaat ve yıkıntı atıklarının granüler dolgu olarak kullanılabilirliğinin değerlendirilmesi. Doktora Tezi, İnönü Üniversitesi, Fen Bilimleri Enstitüsü; 2019.

[25] Ok B, Sarici T, Talaslioglu T, Yildiz A. Geotechnical properties of recycled construction and demolition materials for filling applications. Transportation Geotechnics 2020; 24, 100380. [26] Ok B, Demir A. Yapım Yıkım Atıklarının Yol Temellerinde Kullanılabilirliğinin İncelenmesi. Niğde Ömer Halisdemir Üniversitesi Mühendislik Bilimleri Dergisi 2018; 7(1): 224-236.

[27] TS EN 12350-1. Beton-Taze Betondeneyleri Bölüm 1: Numune Alma. Türk Standartları Enstitüsü, Ankara; 2002.

[28] Vieira CS, Pereira PM. Use of Recycled Construction and Demolition Materials in Geotechnical Applications: A review. Resources. Conservation and Recycling 2015; 103:192204.

[29] Jiménez JR, Ayuso J, Agrela F, López M, Galvín AP. Utilisation of Unbound Recycled Aggregates from Selected CDW in Unpaved Rural Roads. Resources, Conservation and Recycling 2012; 58:88-97.

[30] Neves J, Freire AC, Roque AJ, Martins I, Antunes ML, Faria G. Utilization of Recycled Materials in Unbound Granular Layers Validated by Experimental Test Sections. In: Ninth International Conference on the Bearing Capacity of Roads, Railways and Airfields, Trondheim, Norway; 2013.

[31] Mehrjardi GT, Azizi A, Haji-Azizi A, Asdollafardi G. Evaluating and improving the construction and demolition waste technical properties to use in road construction. Transportation Geotechnics 2020; 23, 100349.

[32] TS 2824 EN 1338. Zemin Döşemesi için Beton Kaplama Blokları - Gerekli Şartlar ve Deney 
Metotları. TSE, Ankara, 2005.

[33] ASTM D 422-63. Standard Test Method for Particle-Size Analysis of Soils. West Conshohocken, USA: ASTM International; 2009.

[34] ASTM D 1241-00. Specification for Materials for Soil-aggregate Sub-base, Base and Surface Courses. West Conshohocken, USA: ASTM International; 2005.

[35] ASTM D 2487-11. Standard practice for classification of soils for engineering purposes (unified soil classification system). West Conshohocken, USA: ASTM International; 2011. [36] ASTM C 127-01 Standard Test Method for Density, Relative Density (Specific Gravity), and Absorption of Coarse Aggregate. West Conshohocken, USA: ASTM International; 2001. [37] ASTM C 128-01. Standard Test Method for Density, Relative Density (Specific Gravity), and Absorption of Fine Aggregate. West Conshohocken, USA: ASTM International; 2001. [38] ASTM D 854-02. Standard Test Methods for Specific Gravity of Soil Solids by Water Pycnometer. West Conshohocken, USA: ASTM International; 2009.

[39] ASTM D 1557. 2012. Standard Test Methods for Laboratory Compaction Characteristics of Soil Using Modified Effort. West Conshohocken, USA: ASTM International; 2012.

[40] ASTM D 4254-00. Standard test method for minimum index density and unit weight of soils and calculation of relative density. West Conshohocken, USA: ASTM International; 2002.

[41] Karayolları Teknik Şartnamesi. Ulaştırma Denizcilik ve Haberleşme Bakanlığı Karayolları Genel Müdürlüğü, Ankara, Türkiye; 2013. 